\title{
LA CELEBRACIÓN DE LOS TRATADOS, GENEALOGÍA Y ACTUALIDAD CONSTITUCIONAL
}

\section{Ricardo MÉNDEZ SILVA}

RESUMEN: El autor realiza un análisis retrospectivo con relación al marco jurídico nacional de la celebración de tratados, desde la Constitución de Cádiz de 1812 hasta la Constitución de 1917, haciendo especial hincapié en tres elementos: en primer lugar, el órgano u órganos que a través de los años y reformas han tenido la facultad de intervenir en la celebración de tratados internacionales. En segundo lugar, el procedimiento en que de acuerdo con lo establecido en dichos documentos se realiza la mencionada celebración de tratados, y en tercer lugar, y no menos importante, la jerarquía que en la actualidad y de acuerdo con nuestra Constitución tienen éstos.
ABSTRACT: The author realize a retrospective analysis in relation to the treaties celebrated in the national juridical law-frame, from the Constitution of Cadiz in 1812 until the Constitution in 1917, remarking special interest in three elements: First, the organ or organs that through the years and reformations have had the ability to intervene in the celebration of international treaties. In second place, the procedure to celebrate the treaties as it is stablished in such documents, and in third place, and not less important, the hierarchy that at the present time and according to our Constitution they can have. 


\section{SUMARIO: I. Planteamiento. II. Los textos constitucionales.}

III. Conclusiones.

\section{PLANTEAMIENTO}

Importa el régimen de celebración de los tratados en virtud de que los procedimientos y formalidades vigentes en la esfera doméstica del Estado determinan los compromisos que con carácter obligatorio asume con sus pares estatales y con organizaciones internacionales.

En este artículo se abordan los procedimientos de conclusión de los tratados a la luz de los distintos textos constitucionales que han existido en México, incluyéndose los de Apatzingán y de Cádiz. ${ }^{1}$ La transcripción de los artículos abordados ha obedecido al interés del autor de compartir con el lector la lectura directa de los textos a fin de que se aprecie la evolución de la regulación.

El régimen de la celebración de los tratados se ha reservado a la soberanía estatal, es decir, corresponde al Estado determinar los órganos internos que participan en la contratación y fijar los procedimientos a seguir. La doctrina anglosajona acuñó el término treaty making power, de aceptación prácticamente universal, para referirse a esta facultad interna. ${ }^{2}$

Sin embargo, el derecho internacional consuetudinario definió en su esfera normativa las etapas principales para la conclusión de los acuerdos, la negociación, la firma y la ratificación, y, en su caso, la adhesión, recurso del Estado para sumarse a un régimen en vigor y del cual no es parte todavía. Asimismo, en la arena internacional se regularon figuras e instituciones como las reservas, y se fueron dando las guías para la interpretación de los tratados.

Mientras prevaleció la vigencia histórica del Estado absolutista, los tratados eran suscritos únicamente por el Ejecutivo sin que mediara revisión o aprobación de un órgano legislativo. Existía la ratificación a cargo del Ejecutivo, con miras a ponderar lo acordado por los negociadores, pero sin que hubiera un control o contrapeso por el Poder Legislativo. El advenimiento del Estado democrático, alumbrado principalmente por la revolución norteamericana de independencia y la Revolución francesa,

1 La revisión de los textos constitucionales se realizó en el volumen elaborado por el maestro Horacio Labastida, Las Constituciones de México, 2a. ed., México, Congreso de la Unión, 1991, 596 pp.

2 Ver Parry, Clive, "The Law of Treaties", Manual of Public International Law, Edited by Max Sorensen, England, Macmillan, 1968, pp. 180 y ss. 
implicó la imposición de limitaciones al Ejecutivo en distintas materias, entre ellas las cuestiones concernientes a las relaciones internacionales, como el nombramiento de embajadores y cónsules, la declaración de guerra y, por supuesto, la celebración de los tratados.

Así, la Constitución norteamericana de 1787, en el apartado relativo a las facultades del presidente, dispuso que tendría "facultad con consejo y consentimiento del Senado, para celebrar tratados, con tal de que den su anuencia dos tercios de los senadores presentes..." . ${ }^{3}$ El régimen constitucional mexicano se inspiró en este modelo, pero desde el principio mostró peculiaridades de interés que no implicaron una copia pasiva de la solución norteamericana.

En la misma línea, la Constitución francesa de 1773 había contemplado la negociación de los tratados a cargo del Consejo Ejecutivo y la "ratificación de los tratados" por parte del cuerpo Legislativo. ${ }^{4}$

Algunas aclaraciones se antojan pertinentes. Conviene distinguir el sentido de los términos "aprobación" y "ratificación". Habitualmente se dedica el de aprobación al trámite interno del órgano Legislativo competente, y el de ratificación para el acto final del Ejecutivo, por el cual un Estado manifiesta en el plano internacional su disposición de obligarse por el tratado, una vez que cuenta con la aprobación legislativa interna. Campea una sinonimia generalizada entre ambos términos, pero la pulcritud conceptual aconseja inclinarse por esta diferenciación. Así lo considera el clásico del derecho de los tratados, Lord Mc. Nair, al referirse a los diferentes significados que se le atribuyen a la ratificación. ${ }^{5}$

Por otra parte, el aceleramiento de las relaciones internacionales ha impuesto la celebración de una amplia variedad de acuerdos internacionales cuya importancia es escasa para el interés general del Estado y suele perfeccionarse jurídicamente sólo con la firma. La Convención de Viena de 1969 sobre el Derecho de los Tratados contempla precisamente la posibilidad de que los tratados entren en vigor a partir de la firma, pero para ello es menester que el sistema constitucional lo admita, ello en congruencia con el principio ya antes expuesto del treaty making power.

3 Segunda sección, párrafo 2.

4 Artículos 70 y 55.

5 "Popularly, the approval of other state organ whose approval may be neccesary; this is an unfortunate use of the word and should be avoided", Mc Nair, The Law of Treaties, Oxford at the Clarendon Press, United Kingdom, 1961, p. 130. 
Antes de reseñar los métodos de conclusión de tratados reconocidos por los ordenamientos constitucionales de México a lo largo de nuestra historia, es de advertirse que hoy día el régimen de la carta magna debe complementarse con la Convención de Viena de 1969 sobre el Derecho de los Tratados, la Convención de Viena de 1985 relativa a los Tratados celebrados por Estados con Organizaciones Internacionales y entre éstas 6 y la Ley de Tratados de 1992, instrumentos que son ley suprema de la Unión, con apego al artículo 133 constitucional.

\section{LOS TEXTOS CONSTITUCIONALES}

\section{La Constitución de Cádiz de 1812}

Aunque este texto no rigió en México y aun en España abrió una época de duras convulsiones políticas, tiene interés, porque no ajena a la influencia de las novedades constitucionales impulsadas por la independencia norteamericana y por la Revolución francesa, concibió una monarquía acotada, en la que el monarca tenía limitaciones en distintos ámbitos, de nuestra incumbencia, en asuntos internacionales. De esta suerte, las contenciones señaladas al rey en esta materia corresponden a una visión democratizadora, no dejarle al Ejecutivo la capacidad de obligar unilateralmente al Estado, sino buscar un equilibrio institucional, el contrapeso necesario y la vigilancia adecuada del Poder Legislativo. A lo largo del desarrollo constitucional mexicano estará presente este modelo, tanto en los instrumentos federales como en los centralistas.

La redacción de este ordenamiento en materia internacional fue sin duda el antecedente de la versión de la Constitución mexicana de 1917, particularmente en lo que dispuso originalmente el artículo 89, fracción X. Concibió como facultad del monarca en el capítulo "De la inviolabilidad del Rey y de su autoridad", la facultad de "Dirigir las relaciones diplomáticas y comerciales con las demás potencias y nombrar los embajadores, ministros y cónsules". ${ }^{7}$

Particularmente sobre la celebración de tratados la Constitución de Cádiz señaló: "No puede el Rey hacer alianza ofensiva, ni tratado especial de comercio con ninguna potencia extranjera sin el consentimiento de

6 Ambas Convenciones fueron ratificadas por México y publicadas en el Diario Oficial de la Federación los días 14 de febrero de 1975 y 28 de abril de 1988, respectivamente.

7 Artículo 171, fracción décima. 
las Cortes", y preveía además: "No puede tampoco obligarse por ningún tratado o dar subsidios a ninguna potencia extranjera sin el consentimiento de las Cortes". 8

Estas limitaciones al Ejecutivo se correlacionaban con una facultad expresa otorgada a las Cortes: "Aprobar antes de su ratificación los tratados de alianza ofensiva, los de subsidios y los especiales de comercio". 9

Ciertamente, el documento gaditano no rigió en México, pero algunas expresiones que pervivieron en nuestros textos constitucionales hallan su simiente en aquel documento, como la ya señalada facultad del presidente de la República de "conducir las negociaciones diplomáticas" en el artículo 89, fracción X. ${ }^{10}$ Tal expresión perviviría la friolera de ciento setenta y seis años, hasta la reforma constitucional de 1988, que incorporó en el máximo ordenamiento los principios de la política exterior mexicana. Asimismo, en el código político español se reconocieron la facultades del rey de "Conceder o negar la admisión de tropas extranjeras en el reino" y la de "nombrar y separar libremente los secretarios de Estado y del Despacho". ${ }^{11}$ Frases que con el necesario maquillaje republicano trascendieron hasta nuestra carta magna.

\section{La Constitución de Apatzingán de 1814}

De construcción y tono congresionales, la Constitución de Apatzingán concedió al Supremo Gobierno la atribución de "Decretar la Guerra y dictar las instrucciones bajo las cuales haya de proponerse o admitirse la paz: las que deben regir para ajustar los tratados de alianza y comercio con las demás naciones, y aprobar antes de su ratificación estos tratados". ${ }^{12}$

Encomendó al Supremo Gobierno, que estaría constituido por tres individuos, "Publicar la guerra y ajustar la paz. Celebrar tratados de alianza y comercio con las naciones extranjeras..." 13 conforme a la disposición anteriormente transcrita.

El Supremo Congreso tenía no sólo la facultad de aprobar los tratados antes de la ratificación (se aprecia un correcto manejo terminológico), sino de dar las instrucciones conforme a las cuales deberían ajustarse los

8 Artículo 172, fracciones V y VI.

9 Artículo 108.

10 Artículo 168, fracción X.

11 Artículo 131.

12 Artículo 108.

13 Artículo 159. 
tratados. Vale la pena destacar que en el régimen prevaleciente, el Senado está facultado para intervenir a posteriori de la negociación, esta última, facultad del Ejecutivo, sin que medie la posibilidad de dar instrucciones para la elaboración de un acuerdo.

\section{El Acta Constitutiva de la Federación y la Constitución de 1824}

El Acta Constitutiva concedió al Supremo Poder Ejecutivo la facultad de "Dirigir las negociaciones diplomáticas, celebrar tratados de paz, amistad, alianza, federación, tregua, neutralidad armada, comercio y otros; más para prestar o negar su ratificación a cualquiera de ellos, deberá proceder la aprobación del Congreso General" . ${ }^{14}$

El Poder Legislativo se visualizaba constituido por una Cámara de Diputados y otra de Senadores, y se le otorgó la facultad exclusiva de “...aprobar los tratados de paz, de alianza, de amistad, de federación, de neutralidad armada, y cualquier otro que celebre el poder ejecutivo"..${ }^{15}$ Es ésta una nota diferencial, digna de advertirse, respecto al modelo norteamericano, en el que desde la etapa fundacional la aprobación se otorgó al Senado, mientras que en nuestros albores constitucionales se le entregó al Congreso en su conjunto.

Disposición correspondiente con el esquema organizativo federal fue la de negarle a las entidades federativas la posibilidad jurídica de asumir directamente compromisos internacionales: "Ningún Estado entrará en transacción o contrato con otro, o con potencia extranjera, ni se empeñará en guerra, sino en caso de actual invasión, o en tan inminente peligro que no admita dilación". ${ }^{16}$

La Constitución Federal de los Estados Unidos Mexicanos, de octubre de 1824, inició su articulado con la proclama de la independencia, condición determinante del Estado emergente: "La Nación mexicana es para siempre libre e independiente del gobierno español y de cualquiera otra potencia". ${ }^{17}$ Nuestro país dejaba tras de sí trescientos años de dominación colonial y toda vez que su independencia era negada por España, es comprensible que su primer postulado constitucional fuera afirmar su libertad e independencia, expresiones consustanciales de la soberanía,

14 Artículo116, fracción II.

15 Artículo 13, párrafo decimoséptimo.

16 Artículo 29.

17 Artículo primero. 
postulado por el que la joven nación debería luchar para asegurar su viabilidad en 1846-1848 y 1862-1867.

Al referirse al Poder Ejecutivo, el Acta Constitutiva había indicado que se depositaría en el individuo o individuos que señalara la Constitución. Dejó abierta la posibilidad de un Ejecutivo colegiado, fórmula empleada como solución política a la caída del emperador Agustín de Iturbide. La carta magna superó la indeterminación y concibió un Ejecutivo unipersonal ${ }^{18}$ con la redacción que prevalece hasta la fecha: "Se deposita el supremo poder ejecutivo de la federación en un solo individuo que se denominará presidente de los Estados Unidos Mexicanos". ${ }^{19}$ Sólo se ha sustituido la palabra "federación" por la de "unión" en el texto vigente.

Junto a la presidencia unimembre se diseñó un Poder Legislativo bicamaral, integrado por una Cámara de Diputados y otra de Senadores. Al Congreso, y no nada más a la Cámara de Senadores, como aparecía en el modelo norteamericano, se le encomendó "Aprobar los tratados de paz, de alianza, de amistad, de federación, de neutralidad armada, y cualesquiera otros que celebre el presidente de los Estados Unidos con potencias extranjeras". ${ }^{20}$

En el texto constitucional irrumpe una curiosidad derivada de la época histórica. El presidente fue facultado para "celebrar concordatos con la silla apostólica" ${ }^{21}$ Sabido es que el concordato es un tipo especial de acuerdo internacional, igualmente obligatorio que un tratado, pero cuya celebración ocurre entre un Estado y el Vaticano; su finalidad es regular dentro del espacio estatal el ejercicio de la fe católica. En su despertar institucional México dejó en la misma Constitución constancia de su catolicismo con un carácter de intolerancia: "La religión de la nación mexicana es y será perpetuamente la católica, apostólica y romana. La nación la protege por leyes sabias y justas, y prohibe el ejercicio de cualquiera otra". 22

Es de entenderse que el trato con los Estados pontificios mereciera atención aparte en la Constitución, pero lo significativo es que estos acuerdos requirieran de instrucciones especiales de parte del Congreso. Mientras en los tratados la participación del Congreso fue a posteriori de

Ver Carpizo, Jorge, Estudios constitucionales, México, UNAM, 1980, pp. 27 y ss.

Artículo 74.

Artículo 50, fracción XIV.

Artículo 50, fracción XIII.

Artículo 3o. 
la negociación, aquí se demandaba expresamente la intervención previa. Decía la Constitución respecto a las facultades del Congreso: "Dar instrucciones para celebrar concordatos con la silla apostólica, aprobarlos para su ratificación, y arreglar el ejercicio del patronato en toda la Federación". ${ }^{23}$

Importa observar que en el campo de la contratación internacional, la aprobación interna se confirió al Congreso y no se estableció una votación calificada como en el vecino país del norte, en donde la votación requerida de dos terceras partes de los senadores presentes ha sido un factor real de control en las relaciones internacionales.

Asimismo, en la carta norteamericana se planteó que los tratados serían celebrados con "el consejo y el consentimiento del Senado". El "consejo" implica que el Senado puede participar en la celebración del tratado antes de que le sea sometido para su aprobación. En el caso mexicano, como se ha visto, ello podía ocurrir sólo tratándose de la negociación de los concordatos.

En lo tocante a la redacción, la Constitución norteamericana empleó únicamente el término genérico "tratados", mientras que los autores de la nuestra optaron por un listado amplio de acuerdos susceptibles de ser adoptados, recuérdese, de paz, amistad, alianza, etcétera, y por si hubiera dudas, "cualesquiera otros".

En la lógica de la preponderancia del sujeto federal en las relaciones con el exterior, y acorde con el Acta Constitutiva, se prohibió a los estados "Entrar en transacción con alguna potencia extranjera, ni declararle guerra, debiendo resistirse en caso de actual invasión, o en tan inminente peligro que no admita demora dando inmediatamente cuenta, en estos casos, al presidente de la República". ${ }^{24}$ En este punto, el precepto se corresponde con la previsión constitucional norteamericana que es la visión generalizada de un régimen federal: "Ningún Estado celebrará tratado, alianza o confederación algunos" ${ }^{25}$

Toda vez que el Estado mexicano se conformó como una unión federal, se apuntó la validez de los tratados en el orden jurídico interno, y aunque no se clarificó una solución de jerarquía de modo explícito, obvio

23 El patronato fue una institución original que rigió durante la época de la Colonia, por la cual la Corona española financiaba las labores de evangelización de la Iglesia y a cambio, proponía a la Santa Sede a los obispos para su designación, y aun la distribución de las diócesis. Gómez Ciriza, Roberto, México ante la diplomacia Vaticana, México, Fondo de Cultura Económica, 1977, pp. 56 y ss.

24 Artículo 162, fracción IV.

25 Artículo primero, décima sección, párrafo primero. 
resulta de la lectura y de la interpretación del artículo respectivo que había preeminencia del régimen federal, incluyéndose los tratados, sobre el ámbito jurídico de las entidades federales: "Cada uno de los Estados tiene obligación... III. De guardar y hacer guardar la constitución y leyes generales de la Unión y los tratados hechos o que en adelante se hicieren por la autoridad suprema de la federación con alguna potencia extranjera". ${ }^{26}$

Los dos instrumentos constitucionales, inaugurales del Estado mexicano, revisten interés singular, además, porque sustituidos en 1836 y en 1843 , fueron puestos en vigor nuevamente en 1847. A su amparo se celebró el Tratado de Guadalupe Hidalgo de 2 de febrero de 1848.

\section{Constitución de 1836}

La estructura federal del Estado le cedió el paso a un modelo de organización centralista, pero en lo tocante al régimen de celebración de tratados la nueva Constitución continuó con lo dispuesto por su antecesora.

El Poder Ejecutivo fue encomendado a "un supremo magistrado" que se denominó presidente de la República ${ }^{27}$ y se constituyó el Poder Legislativo a través de un "Congreso General de la nación” compuesto por dos cámaras, la de Diputados y la de Senadores. ${ }^{28}$

El presidente de la República recibió la facultad de "Dirigir las negociaciones diplomáticas y celebrar tratados de paz, amistad, alianza, tregua, neutralidad armada, sujetándolos a la aprobación del congreso antes de su ratificación". ${ }^{29}$

La vinculación normativa necesaria reconoció como atribución exclusiva del Congreso General: "Aprobar toda clase de tratados que celebre el ejecutivo con potencias extranjeras y los concordatos con la silla apostólica". ${ }^{30}$ No aparece en esta disposición la exigencia de que el Congreso diera las bases para la conclusión de los concordatos, tal como lo contempló la carta de 1824, pero en las atribuciones del presidente sí se introdujo tal limitante: "Celebrar concordatos con la silla apostólica, arreglado a las bases que le diere el congreso". ${ }^{31}$ 
Toda vez que la de 1836 fue una Constitución centralista no campeó la necesidad de prohibir a las provincias la celebración de tratados, llamadas en el texto "Departamentos". No sobra aludir a que el régimen centralista de 1836 fue uno de los detonantes del movimiento secesionista de los texanos y de la tragedia todavía por venir justo diez años después.

\section{Bases de Organización Política de la República Mexicana de 1843}

En la secuencia centralista, de corte conservador, se dio a luz un nuevo ordenamiento constitucional. Al igual que en el caso inmediato anterior, no surgieron innovaciones significativas en el régimen de tratados, ello porque las inquietudes dominantes del vivir político era la estructura del Estado y la organización de poder público.

El Supremo Poder Ejecutivo se depositó en un magistrado denominado "presidente de la República". ${ }^{32}$ El Poder Legislativo se instituyó en "un congreso dividido en dos cámaras, una de diputados y otra de senadores...".33

El presidente de la República recibió la obligación de "Dirigir las negociaciones diplomáticas, y celebrar tratados de paz, amistad, alianza, tregua, neutralidad armada y demás convenios con las naciones extranjeras, sujetándolas a la aprobación del congreso antes de su ratificación", ${ }^{34}$ y fue facultad del Congreso "Aprobar, para su ratificación toda clase de tratados que celebre el ejecutivo con las potencias extranjeras". ${ }^{35} \mathrm{Y}$ en lo concerniente a los concordatos se previó la aprobación por el Congreso, antes de su ratificación "y arreglar el ejercicio del patronato en toda la Nación". 36

La redacción es más o menos la misma que en los dos documentos anteriores, pero se usó la palabra "convenio", que es uno de los tantos sinónimos del término "tratado" ${ }^{37}$ Tampoco se previó la facultad del Congreso tendiente a dar instrucciones para la negociación de los concordatos, pero al igual que en la Constitución de 1836, en el capítulo de obligaciones del presidente sí se estipuló "Celebrar concordatos con la silla

32 Título V, artículo 83.

33 Título IV, artículo 25.

34 Artículo 86, fracción XVI.

35 Artículo 66, fracción IX.

36 Artículo 66, fracción X.

37 Para el acto de la concertación internacional nos topamos con un buen número de términos sinónimos, verbi gratia: convención, convenio, acuerdo, carta, pacto, protocolo, declaración, etcétera. 
apostólica, sujetándolos a la aprobación del congreso". ${ }^{38}$ En este punto se homologó el régimen con el general de los tratados, al no exigirse que el Congreso emitiera instrucciones previas para su confección, lo que implicó una variante respecto a la exigencia original de 1824 .

Apareció en el ordenamiento de 1843 una prohibición expresa al Ejecutivo: "No puede el presidente... Enajenar, ceder, permutar o hipotecar parte alguna del territorio de la República" ${ }^{39}$ Sólo en la Constitución de Apatzingán de 1814 se halla una disposición parecida. Se estipulaba que las provincias integrantes del Estado "no podrán separarse unas de otras en su gobierno, ni menos enajenarse en todo o en parte". ${ }^{40}$ Sin embargo, en las Bases Orgánicas se manejó una prohibición circunstanciada al presidente de la República para enajenar, ceder, permutar o hipotecar territorio nacional. Obviamente, la disposición se inspira en la desconfianza que despertó el general Antonio López de Santa Anna durante la desastrosa campaña de Texas.

\section{Acta de Reformas Constitucionales de 1847}

Después de los sacudimientos políticos y de las oscilaciones constitucionales, en plena guerra con los Estados Unidos, este instrumento reivindicó la constitucionalidad primordial de 1824. El preámbulo de este documento histórico reza: "Que aquél pacto de alianza, origen de la primera Constitución y única fuente legítima del Poder Supremo de la República, subsiste en su primitivo vigor, y es y ha debido ser el principio de toda institución fundamental". En la misma parte introductoria se lee el enfático postulado: "Que la acta constitutiva y la Constitución Federal, sancionadas el 31 de enero y 4 de octubre de 1824, forman la única Constitución política de la República". ${ }^{41}$ El dispositivo concerniente a la celebración de los tratados es, consecuentemente, el abordado en el inciso 2. 3, relativo a la Constitución de 1824.

En relación con el Poder Ejecutivo, el Acta de Reformas eliminó el cargo de vicepresidente y previno que la falta del presidente debería ser cubierta por el presidente de la Corte Suprema de Justicia. ${ }^{42}$ El dato de-

38 Artículo 87, fracción XVIII.

39 Artículo 89, fracción IV.

40 Artículo 43.

41 Párrafo III.

42 Artículo 15, "Se derogan los artículos de la Constitución que establecieron el cargo de Vicepresidente de la República, y la falta temporal del Presidente se cubrirá por los medios que ella esta- 
viene interesante porque a cuatro meses de haberse adoptado el Acta, el general Santa Anna renunció a la presidencia de la República, tras la batalla de Chapultepec con la que cayó la ciudad de México en manos del ejército invasor. Con arreglo a la reforma constitucional, asumió la presidencia de la República don Manuel de la Peña y Peña, a la sazón presidente de la Corte Suprema de Justicia de la Nación, y a cuya responsabilidad quedó una de las más ingratas tareas de nuestra historia: dirigir las negociaciones para la conclusión del Tratado de Guadalupe Hidalgo por el que México perdió más de la mitad del territorio.

Si bien el Acta de Reformas no incluyó ninguna mención al régimen de los tratados, y se estuvo a lo dispuesto por la Constitución de 1824, es decir, con la participación de ambas cámaras para su aprobación, sobresale la introducción de un recurso de inconstitucionalidad que podían presentar el presidente, de acuerdo con sus ministros, los diputados, los senadores o las legislaturas, contra una ley del Congreso General. Este recurso sería utilizado contra el Tratado de Guadalupe Hidalgo, por lo que conviene tener a la vista el texto:

Si dentro de un mes de publicada una ley del congreso general, fuere reclamada como anticonstitucional, o por el presidente de acuerdo con su Ministerio, o por diez diputados, o seis senadores, o tres legislaturas, la Suprema Corte, ante la que se hará el reclamo, someterá la ley al exámen de las legislaturas, las que dentro de tres meses, y precisamente en un mismo día, darán su voto. Las declaraciones se remitirán a la Suprema Corte, y ésta publicará el resultado, quedando anulada la ley, si así lo resolviera la mayoría de las legislaturas. ${ }^{43}$

Desborda interés el recurso en cuestión porque: $a$ ) la iniciativa para interponerlo se concedía al Poder Ejecutivo y al Legislativo, referido a diputados o senadores, y a las legislaturas de los estados contra una ley del Congreso; b) El recurso debería presentarse ante la Corte Suprema de Justicia, y no es concebible que su injerencia fuera de mero trámite, sino que debería analizar su procedencia antes de turnarla a las legislaturas de los estados; c) Pero una vez turnado el recurso, las legislaturas por mayo1824 contemplaban la suplencia del presidente y del vicepresidente por el presidente de la Corte Suprema de Justicia.

43 Artículo 23. 
ría (no habla de una mayoría calificada) tenían la última palabra sobre la constitucionalidad de una ley.

El Tratado de Guadalupe Hidalgo fue aprobado en mayo de 1848 tanto por la Cámara de Diputados como por la de Senadores. La oposición al tratado fue particularmente sensible en la Cámara de Diputados, donde obtuvo una votación de 51 votos a favor contra $35 .{ }^{44}$ Once de los diputados opositores presentaron el recurso de inconstitucionalidad contra el Tratado de Guadalupe Hidalgo. ${ }^{45}$ Por desgracia, a pesar de la pulcritud de sus razonamientos y de la gallardía de su acción, en términos realistas el país estaba derrotado en todos los frentes, y en Estados Unidos prosperaba la posición de exigir más territorio a México que el pactado en el tratado, incluso una tendencia política en el vecino país abogaba por la incorporación de todo México a la Unión Americana, postura que no dejó de encontrar algunos seguidores en México. ${ }^{46}$

El recurso de inconstitucionalidad, además, aunque presentado a tiempo, fue elevado a la Corte Suprema, con fecha 1o. de junio, un día después de que se intercambiaron los instrumentos de ratificación, el 30 de mayo en Querétaro, ${ }^{47}$ lo que creaba de pasada una situación jurídica conflictiva, un tratado internacional en vigor, susceptible de ser anulado en lo interno, en un entorno de estrepitosa derrota militar. Habrá otra oportunidad de analizar este episodio judicial. Baste por ahora decir que la Corte asumió una posición formalista y cerró el paso al recurso bajo el argumento de que "No hay principio más incontestablemente aceptado que la inadmisibilidad de la participación de las legislaturas de los estados en las relaciones internacionales". Recuérdese que a las legislaturas de los estados tocaba la facultad de declarar la inconstitucionalidad de una ley. Por añadidura, la Corte arguyó que el tratado no era una ley, ${ }^{48} \mathrm{en}$

44 Archivo Histórico Diplomático Mexicano, Algunos documentos sobre el Tratado de Guadalupe, México, Porrúa, 1971, p. 405.

45 Dejo constancia de los nombres de los diputados promoventes del recurso: Ignacio Muñoz Campuzano, Gerónimo Elizondo, Eugenio María de Aguirre, Manuel Doblado, Vicente Rodríguez, José María Herrera y Zavala, José María del Río, Ponciano Arriaga, José María Mateos, Anastasio Cañedo, Ignacio P. Villanueva. Idem.

46 Sobarzo, Alejandro, Deber y conciencia, Nicolás Trist, el negociador norteamericano en la guerra del 47, 2a. ed., México, Fondo de Cultura Económica, 1996, p. 287.

47 Archivo Histórico Diplomático Mexicano, op. cit. nota 44, p. 405.

48 Estos documentos curiosamente no se encuentran en el Archivo de la Suprema Corte de Justicia de la Nación, pero fueron publicados por el Archivo Histórico Diplomático de México, op. cit., nota 44 . 
sentido estricto, y por lo mismo no podía ser objeto del recurso de inconstitucionalidad.

\section{La Constitución de 1857}

La Constitución liberal de 1857, de extracción laica y distinguida por el brillante catálogo de garantías individuales, depositó “el Supremo Poder Ejecutivo de la Unión en un solo individuo, que se denominará presidente de los Estados Unidos Mexicanos",49 y entre las facultades que le fueron concedidas se encontraba la ya conocida por nosotros de "Dirigir las negociaciones diplomáticas y celebrar tratados con las potencias extranjeras, sometiéndolos a la ratificación del Congreso Federal" ${ }^{50}$

En la concepción estructural del Estado, la Constitución previó un Congreso unicamaral y éste recibió la atribución de "aprobar los tratados, convenios o convenciones diplomáticas que celebre el Ejecutivo". ${ }^{51}$ Más adelante se trata la reforma constitucional de 1874, que transformó al Congreso en bicamaral, introduciendo al Senado.

Por lo pronto, en el antecitado artículo es notorio el empleo de la palabra "ratificación" para la facultad del Congreso, cuando los textos constitucionales anteriores habían manejado con mayor pericia el término "aprobación". Asimismo, contiene las expresiones "convenios" y "convenciones diplomáticas". Dejó de utilizarse la lista particularizada de distintos tipos de tratados (de paz, de guerra, de neutralidad, etcétera) y se asumieron estas expresiones genéricas, cuya adopción no fue fruto de la casualidad. En las deliberaciones del constituyente se insistió en que todos los tratados que celebrara el presidente de la República fueran sometidos al conocimiento del Congreso, ello en virtud de la experiencia negativa que había arrojado la celebración de acuerdos para constituir las comisiones de reclamaciones con otros países para otorgarle a sus súbditos indemnizaciones por los daños sufridos en territorio nacional, atribuibles al poder público. Las compensaciones negociadas fueron gravosas, abusivas y en más de una ocasión armadas de modo fraudulento por los quejosos. ${ }^{52}$ Así, el empleo de los términos "convenios" y "negociaciones

49 Artículo 75.

50 Artículo 85, fracción X.

51 Artículo 72, fracción VIII.

52 Ver Archivo Histórico Diplomático Mexicano, Dos reclamaciones internacionales fraudulentas contra México, con un estudio preliminar de César Sepúlveda, México, Secretaría de Relaciones Exteriores, 1965, p. 263. 
diplomáticas", junto al de "tratados", persiguió que todo tipo de acuerdos pasaran por el control del Congreso. ${ }^{53}$

También es de hacerse notar que el texto, cuando se refiere a la ratificación por el Congreso, no se inclinó por la fórmula "con el consejo de", a la usanza norteamericana, y que hubiera posibilitado la injerencia del Congreso durante el periodo de las negociaciones. De hecho, Ponciano Arriaga (recuérdese que fue uno de los once diputados que interpusieron el recurso de inconstitucionalidad contra el Tratado de Guadalupe Hidalgo), abogó por esta limitante, habiendo tenido en mente el trance dramático de la negociación del Tratado de Guadalupe Hidalgo que marginó al Congreso y el cual fue entregado al pleno de cada cámara para su aprobación en un típico acto de mayoriteo. Zarco sostuvo la postura opuesta, defendió el sigilo que deben cubrir a las negociaciones diplomáticas y solicitó un voto de confianza para la institución del Ejecutivo. ${ }^{54}$ De todas suertes, el Congreso quedaba, como ahora lo está, en aptitud de participar en la fase de la aprobación, lo que implica la posibilidad no sólo de aprobarlo, sino de rechazarlo y de modificarlo para que su contenido fuera renegociado o, en nuestros días, a la luz de los tratados multilaterales, se interpusieran las reservas correspondientes.

Tal como se anticipó, el 13 de noviembre de 1874 procedió la reforma constitucional que introdujo al Senado, con lo que el Poder Legislativo adquirió índole bicamaral. El artículo 72 comprendió dos secciones adicionales, al haberse redefinido la estructura del Poder Legislativo. Al lado de las atribuciones del Congreso se comprendieron la de las Cámara de Diputados y las de la Cámara de Senadores. Nos interesan, por supuesto, las relativas a las facultades exclusivas del Senado: “Aprobar los tratados y convenciones diplomáticas que celebre el Ejecutivo con las potencias extranjeras". ${ }^{5}$ Pasó entonces esta facultad del Congreso, explícitamente al Senado, pero como seguramente en aquellas épocas también se legislaba de prisa, se olvidó eliminar el párrafo XIII del artículo 72, que concedía tal facultad al Congreso General, y tampoco se realizó el ajuste correspondiente al que contenía las facultades y obligaciones del presidente, donde se siguió leyendo que los tratados demandaban "la ratificación del Congreso federal". ${ }^{56}$

53 Méndez Silva, Ricardo, "La Constitución Política mexicana y los tratados”, Obra jurídica mexicana, México, Procuraduría General de la República, 1988, pp. 4709-4736.

54 Idem.

55 Fracción I, sección A del artículo 72.

56 Artículo 85, fracción X. 
La reforma de 1874 adoleció de técnica jurídica y provocó ese evidente contrasentido, pero lo increíble es que el Constituyente del 1917 retomó los mismos errores y reprodujo los textos sin ningún ajuste. Fue hasta 1988 cuando se subsanaron las insuficiencias reseñadas con motivo de la inclusión de los principios de la política exterior en la Constitución Política. ${ }^{57}$ No obstante que la razón de la contradicción sobreviviente caía por sí misma, persistieron confusiones en la práctica. Recuerdo una mesa redonda en la que un alto funcionario de la Secretaría de Relaciones Exteriores manifestó su extrañeza por la ambivalencia en la Constitución, pero afirmó ufano que a él le constaba que en la realidad era el Senado el órgano que aprobaba los tratados. Esto a fines de los años setenta.

La Constitución de 1857 estableció una novedad en materia de crédito externo. El Congreso recibió la facultad de "dar bases sobre las cuales el Ejecutivo pueda celebrar empréstitos sobre el crédito de la Nación; para aprobar esos mismos empréstitos, y para reconocer y mandar pagar la deuda nacional". ${ }^{58}$ Todavía hoy, en la Constitución vigente se lee la misma redacción, con un añadido relativo a las características y requisitos que deben cumplir los empréstitos. ${ }^{59}$

Mayor interés ofrece la prohibición de celebrar ciertos tratados relacionados con garantías individuales. Nota diferencial de la Constitución de 1857 fue precisamente la incorporación de una parte dogmática sobre derechos del hombre que resplandece por la visión ideológica avanzada. Fue prohibida la celebración de tratados para la extradición de reos políticos y la de aquellos delincuentes del orden común que hubieran tenido, en el país en donde cometieron el delito, la condición de esclavos; se prohibía también la celebración de convenios o tratados en virtud de los que alteraran las garantías y derechos que la Constitución otorgaba al hombre y al ciudadano. Con ligeras adaptaciones en la redacción, el texto de aquel artículo 15 fue reproducido en la Constitución de 1917 con idéntico numeral.

La prohibición de celebrar tratados para la expulsión de esclavos se emparenta con un precedente de las Bases Orgánicas de 1843: "Ninguno

57 Rabasa, Emilio O., “Artículo 89”, Constitución Política de los Estados Unidos Mexicanos comentada, 5a. ed., México, Procuraduría General de la República- Instituto de Investigaciones Jurídicas, 1994, p. 403.

58 Artículo 72, fracción VIII.

59 El artículo 73, fracción VIII, dispone: "Ningún empréstito podrá celebrarse sino para la ejecución de obras que directamente produzcan un incremento en los ingresos públicos, salvo los que se relacionen con propósitos de regulación monetaria, las operaciones de conversión y las que se contraten durante alguna emergencia declarada por el Presidente de la República en los términos del Artículo 29". 
es esclavo en el territorio de la nación, y el que se introduzca, se considerará en la clase de libre, quedando bajo la protección de las leyes" ${ }^{60}$ Esta idea nutricia fue reelaborada y plasmada con mayor contundencia en la carta de 1857: "En la República todos nacen libres. Los esclavos que pisen territorio nacional, recobran por solo ese hecho su libertad y tienen derecho a la protección de las leyes" ${ }^{61}$ Más tarde, el artículo 2o. de la Constitución vigente, leal a los antecedentes transcritos, postula: "Está prohibida la esclavitud en los Estados Unidos Mexicanos. Los esclavos del extranjero que entren al territorio nacional alcanzarán, por ese solo hecho, su libertad y la protección de las leyes".

Este precepto resume tendencias filosóficas y luchas históricas, honra la abolición de la esclavitud de Miguel Hidalgo en el bando de 6 de diciembre de 1810 y le dio la jerarquía constitucional en 1857, mientras en los Estados Unidos de Norteamérica, el país del progreso, la esclavitud era legal y, por lo mismo, nuestra salvaguarda jurídica a favor de los esclavos tenía un significado esplendoroso de tutela real.

Por otra parte, en lo tocante a los tratados que prohíben la extradición de reos políticos, era una tendencia que se abría paso a mediados del siglo XIX y cuya primera manifestación normativa fue una ley de Bélgica de 1856. ${ }^{62}$ Así, es posible sostener que la Constitución Política de 1857 fue la primera en reconocer el principio en el estadio constitucional.

Procede apuntar que la prohibición para celebrar tratados que alteren las garantías individuales la he entendido ${ }^{63}$ en el sentido de que las restrinjan y no de que las amplíen. En esta época en la que existe una intensa producción de convenciones en materia de derechos humanos lo natural es que los regímenes internacionales amplíen la cobertura de protección.

En consonancia con lo ya establecido en la Constitución de 1824, se reiteró la prohibición a las entidades federativas de "Celebrar alianza, tratado o coalición con otro Estado ni con potencias extranjeras. Exceptuándose la coalición que puedan celebrar los Estados fronterizos para la guerra ofensiva o defensiva contra los bárbaros". ${ }^{64}$

60 Artículo 9, fracción I.

61 Artículo 20.

62 "La primera excepción a la no extrabilidad del responsable de un delito político, en el plano de los ordenamientos internos, fue contemplada en la Ley Belga del 22 de marzo de 1856... hasta volverse casi de general aplicación precisamente con la denominación de la cláusula belga", Imaz, Cecilia, La práctica del asilo y del refugio en México, México, Potrerillos Editores, 1995, p. 29.

63 Méndez Silva, op. cit., nota 53.

64 Artículo 111. En 1857. 
Finalmente, en el dispositivo constitucional sobresale el artículo 126, alusivo al principio de la supremacía federal, ya esbozado en la Constitución de 1824 y que daría vida al célebre, actual artículo 133. En 1857 se consignó: "Esta Constitución, las leyes del Congreso de la Unión que emanen de ella y todos los tratados hechos o que se hicieren por el presidente de la República con aprobación del Congreso, serán la ley suprema de toda la Unión. Los jueces de cada Estado se arreglarán a dicha Constitución, leyes y tratados a pesar de las disposiciones en contrario que pueda haber en las Constituciones o leyes de los Estados". En esta redacción se percibe meridiana la influencia de la Constitución norteamericana. Y al igual que la Constitución de 1824 planteó la supremacía federal, mas no ofrece un escalonamiento al interior del núcleo normativo federal.

\section{La Constitución Política de 1917}

Las discusiones en el Constituyente de 1916 y 1917, lo mismo que el gran debate constitucionalista a lo largo del siglo XIX, versaron sobre la organización del Estado, el sistema de pesos y contrapesos entre los poderes, los equilibrios entre los factores reales de poder, las limitaciones económicas y la tutela a las clases sociales. A pesar de que durante la Revolución mexicana se vivieron episodios diplomáticos dramáticos, como la invasión norteamericana a Veracruz en 1914 y la llamada "expedición punitiva" del general Pershing en 1916, entre otros incidentes de envergadura, y que dieron pie a la doctrina Carranza ${ }^{65}$ expuesta por el Primer Jefe el 1o. de septiembre de 1918, en contra de la intervención en asuntos internos, la Constitución Política no incluyó un capítulo sobre cuestiones específicamente internacionales. Al contrario, cuestiones relativas a la declaración de guerra, al nombramiento de embajadores y a la celebración de tratados, y aun la facultad de otorgar patentes de corso que se habían prohibido desde la Declaración de Guerra Marítima de París, de 1856, se copiaron inercialmente del texto de 1857 que, a su vez, acarrea expresiones que, como se ha visto, se identifican desde la Constitución de Cádiz.

De este modo, al Ejecutivo, al presidente de la República, se le concedió la facultad de "Dirigir las negociaciones diplomáticas y celebrar tratados con las potencias extranjeras, sometiéndolas a la ratificación del

65 Ver Seara Vázquez, Modesto, Síntesis del derecho internacional público, México, UNAM, 1965 , p. 71. 
Congreso General". ${ }^{66} \mathrm{Al}$ Senado, siguiendo la reforma de 1874, se le otorgó como facultad exclusiva "Aprobar los tratados y convenciones diplomáticas que celebre el presidente de la República con las potencias extranjeras" ${ }^{67}$ Ya el lector recuerda la contradicción que se originó en 1874 y que se repitió en 1917. Es más, en la redacción original del artículo 133 se incluyó también la aprobación por parte del Congreso, y no, como debía ser, por el Senado.

Por otra parte, la facultad concedida al presidente de la República de "dirigir las negociaciones diplomáticas", con el tiempo se antojaba limitativa de las funciones del Ejecutivo en la arena internacional. Más allá de las "negociaciones diplomáticas", el Ejecutivo realiza definiciones y pronunciamientos a nombre del Estado, participa individualmente en el reconocimiento de Estados y de gobiernos, es responsable de las posturas asumidas en organizaciones internacionales.

También la expresión "potencias extranjeras" revelaba resonancias decimonónicas. Desde la última cuarta parte del siglo XIX empezaron a aparecer las organizaciones internacionales públicas, cuya era despegó notablemente con la Sociedad de las Naciones y la Organización Internacional del Trabajo en 1919. Estas formaciones jurídicas internacionales asumieron la calidad de sujetos del derecho internacional y, consecuentemente, estuvieron en aptitud de celebrar tratados.

Con todo, la redacción subsistió, no obstante el mosaico de reformas constitucionales que con el correr de las décadas se plasmó en el ordenamiento constitucional. No fue hasta 1988 cuando se incorporaron los principios de la política exterior a la Constitución y se remozó y actualizó el texto. ${ }^{68}$ En el Diario Oficial de 11 de mayo se publicó la reforma del artículo 89, fracción X, relativo a las facultades del presidente de la República, donde quedó asentado: "Dirigir la política exterior (en lugar de 'las negociaciones diplomáticas') y celebrar tratados internacionales (antes decía sólo 'tratados', lo que era correcto ya que la expresión 'tratados internacionales' se antoja tautológica), ${ }^{69}$ sometiéndolos a la aprobación del Senado". Aquí se eliminó la mención a las potencias extranjeras. La

66 Artículo 89, fracción X.

67 Artículo 76, fracción I.

68 Méndez Silva, Ricardo, "Bases constitucionales de la política exterior”, Problemas actuales del derecho constitucional, México, UNAM, 1994, pp. 253-275.

69 Kelsen distingue el tratado del contrato y reserva para el acto de concertación de voluntades sea entre personas o Estados el genérico de convención. Kelsen, Hans, El contrato y el tratado, México, Editora Nacional, 1974, p. 1. 
omisión posibilita la ubicación de tratados o acuerdos de validez internacional con organizaciones internacionales públicas o, incluso, con otros sujetos relativos del orden jurídico internacional, como los gobiernos de pueblos coloniales o de pueblos sujetos a ocupación extranjera; se cambió el término "ratificación" por el de "aprobación", y en lugar de "Congreso Federal" se escribió finalmente "Senado", como siempre debió haber sido. La nueva redacción experimentó una clara mejoría.

Aprecio varios puntos de interés en la celebración de los tratados.

i) Recientemente la Suprema Corte de Justicia de la Nación aclaró que la firma de un tratado no es preciso que la realice el presidente de la República en forma personalísima. ${ }^{70} \mathrm{El}$ criterio fue suscitado porque el quejoso alegaba la inconstitucionalidad de un tratado que había sido firmado por el secretario de Relaciones Exteriores, en lugar de haber sido signado por el presidente de la República. La Corte sostuvo la siguiente tesis: "TRATAdo de Extradición Internacional celebrado entre México y Estados UNIDOS DE NORTEAMÉRICA EL CUATRO DE MAYO DE MIL NOVECIENTOS SETENTA Y OCHO. NO ES INCONSTITUCIONAL POR LA CIRCUNSTANCIA DE QUE EL PRESIDENTE DE LA REPÚBLICA NO LO HAYA SUSCRITO PERSONALMENTE, SI INSTRUYÓ AL SECRETARIO DE RELACIONES EXTERIORES PARA SU NEGOCIACIÓN Y LUEGO LO RATIFICÓ PERSONALMENTE".

El criterio antecitado no es un ejercicio meramente intelectual. No obstante que en 1998 la Corte lo adoptó, dispongo de información fidedigna respecto a que el Acuerdo Global entre México y la Unión Europea que entró en vigor el 10. de octubre del 2000, enfrentó una seria oposición en el Senado, precisamente bajo el pretexto de que en su momento no había sido firmado de manera personal por el presidente de la República. Al parecer nadie se acordó del precedente ilustrador de la Corte, y la discusión se fue por otros rumbos argumentales, con final feliz.

ii) Otro punto a analizar es si el Senado debe seguir siendo el único órgano que apruebe los tratados o si debe extenderse el régimen de aprobación a la Cámara de Diputados.

En aras de un flujo expedito sería pertinente que la aprobación corriera a cargo del Senado exclusivamente. Asimismo, se ha entendido que la Federación toda participa en la aprobación de los tratados en virtud de que los senadores representan en condiciones de igualdad a cada una de las entidades.

70 Ver Méndez Silva, Ricardo, "La firma de los tratados”, Cuestiones Constitucionales, México, núm. 3, 2000, pp. 209-228. 
Pero en sentido contrario puede argüirse que hoy día prevalecen nuevas realidades que deben apreciarse y que agrupo del modo siguiente:

a) Los compromisos que asume el Estado tienen mayor trascendencia para la sociedad y su proyecto comunitario. Verbigracia, el Tratado de Libre Comercio con los Estados Unidos y Canadá, independientemente de la valoración que se conceda a sus frutos, fue un cambio de orientación al sistema económico, comercial y financiero.

b) Precisamente algunas materias comprendidas dentro del Tratado de Libre Comercio, el comercio mismo, la inversión extranjera, la transferencia de tecnología, la propiedad intelectual, son facultad del Congreso de la Unión; ${ }^{71}$ sin embargo, regímenes sobre tales materias se adoptan por la vía de un tratado cuya confección demandaría la participación de la Cámara de Diputados. Ciertamente, el tratado es un método heterodoxo de creación legislativa, se crea una ley, ${ }^{72}$ una ley suprema de la Unión, con el concurso de una sola cámara sin que la carta magna acote o restrinja los contenidos sobre los que puede versar un tratado. El punto asume mayor interés porque un reciente criterio de la Suprema Corte interpreta que los tratados se encuentran en un rango superior a las leyes que emanan de la Constitución (esta tesis será considerada más adelante).

c) Recientemente Diego Valadés publicó un artículo ${ }^{73}$ donde analiza el trámite de aprobación y ratificación de los tratados en diferentes sistemas federales.

En América Latina, de nueve países que siguen un modelo bicamaral, sólo en nuestra Constitución la aprobación se encomienda a una sola de las cámaras. Y en la Unión Europea, sólo Austria, en el caso de países que tienen un sistema bicamaral, se apoya en una sola cámara para la aprobación,

d) Según se ha observado en esta revisión retrospectiva de nuestros textos constitucionales, históricamente la aprobación de los tratados fue competencia del Congreso en 1814, 1824, 1836, 1843 y en 1847 cuando se reimplantó la vigencia de la ley fundamental de 1824 . No

71 Artículo 73 constitucional.

72 La Pérgola, Antonio, Constitución del Estado y normas internacionales, México, UNAM, 1985 , pp. 25 y ss.

73 Valádes, Diego, “Asimetrías en el Congreso”, Excélsior, México, 27 de marzo del 2000. 
sería entonces nuevo para México esta regulación que prosperó en los cimientos de nuestro vivir constitucional.

e) Finalmente, se asienta que la sociedad mexicana experimenta un proceso de cambio y de amplitud democrática, y aunque ésta ya es palpable en el Senado, antes cerrado a una preponderancia evidente del Partido Revolucionario Institucional, la Cámara de Diputados es un centro vibrante del acontecer democrático de la nación. Darle juego a la Cámara de Diputados en este campo iría en consonancia con los tiempos históricos que vivimos. Este último argumento se lo escuché desde 1978 a Antonio Carrillo Flores, quien tuvo siempre la lucidez del jurista visionario. Fue en una mesa redonda organizada por el Instituto Matías Romero de la Secretaría de Relaciones Exteriores y de la cual se editó una memoria. ${ }^{74}$

iii) Por supuesto, una reforma constitucional en la materia debería abordar diversos puntos, en el contexto más amplio de una nueva constitucionalidad, y no seguir con el hábito insatisfactorio de los parches normativos. En tanto ello ocurriera, debería exigirse una mayor atención al Senado de la República en la revisión de los tratados que se someten a su conocimiento. La lectura de los dictámenes que aprueba esta Cámara revela que con mínimas modificaciones suelen reproducirse los planteamientos que hace la Secretaría de Relaciones Exteriores. Toda vez que los tratados van a comprometer al Estado y que con arreglo a la Convención de Viena de 1969 sobre el Derecho de los Tratados no se puedan alegar contra su observancia disposiciones jurídicas del orden interno; por ello, una revisión detallada del quehacer del Ejecutivo es una obligación intransferible. Bernardo Sepúlveda ${ }^{75}$ abordó el caso de los APPRI (Acuerdos Bilaterales para la Promoción y Protección Recíproca de Inversiones), cuya finalidad es permitir a una empresa extranjera acudir ante un tribunal de arbitraje internacional, eludiendo la jurisdicción del Estado, lo que rompe la igualdad entre nacionales y extranjeros y atenta contra una norma constitucional, la Cláusula Calvo. Celebrados estos acuerdos con varios países, pasaron al Senado, en donde no valieron los

74 Carrillo Flores, Antonio, "Comentarios a la exposición de don Antonio Martínez Báez sobre las funciones del Congreso en la vida internacional de México", La Constitución y las relaciones exteriores de México, México, Secretaría de Relaciones Exteriores, 1978, pp. 31 y 32.

75 Texto inédito, conferencia impartida en la cátedra magistral Julio Cortázar, Universidad de Guadalajara, México, 20 de septiembre del 2000. 
argumentos aislados que se esgrimieron sobre la inconstitucionalidad de estos tratados.

La Pérgola ${ }^{76}$ advierte que en virtud del flujo mayor de obligaciones derivadas de tratados, los parlamentos suelen contar con órganos técnicos especializados que revisan profesionalmente la compatibilidad de los acuerdos internacionales con la normatividad interna. Es decir, más allá de las comisiones competentes del Senado debería existir un comité de expertos que brindara un análisis exhaustivo, técnico y apolítico. Lo anterior, no sólo por la posibilidad de errores, sino incluso por las aprobaciones decididas por mayoriteo, inducidas políticamente a sabiendas de su inconstitucionalidad.

iv) Paradójicamente con lo expuesto, debería explicitarse un régimen para que determinados acuerdos pudieran entrar en vigor sólo con la firma del Ejecutivo. Ello cuando se tratara de cuestiones administrativas de índole menor que no planteen una reglamentación general. Este tipo de acuerdos son conocidos como "acuerdos administrativos" o "acuerdos ejecutivos". Los más socorridos son los que eximen de visas a los viajeros, establecen servicios de asesoría en ciertos campos, como el comercio exterior, programas de cooperación cultural, de servicios postales, programas de intercambio de estudiantes, los mecanismos para el intercambio de valijas diplomáticas, establecimiento de comités para la colaboración en situaciones de desastres naturales, medidas técnico-administrativas para facilitar las notificaciones de vuelos sin itinerario, etcétera.

La amplitud de la vida internacional conlleva negociaciones y acuerdos de menor trascendencia y solemnidad a las de los tratados tradicionales, en las variadas esferas administrativas de los países. Con todo, en nuestra Constitución Política no están previstos, antes al contrario, la expresión "tratados internacionales y las convenciones diplomáticas", en el artículo 76, según se vio, fue introducida en el Constituyente de 1857 con el propósito manifiesto de que todo tipo de acuerdos fueran conocidos por el Congreso. Claro que a mediados del siglo XIX la dinámica internacional no mostraba la aceleración de nuestra época.

Aun cuando los acuerdos administrativos no están contemplados en la escala constitucional, no impide que sean celebrados por secretarías de Estado y, más aún, por gobernadores de las entidades federativas, e incluso por presidentes municipales, sobre todo en las áreas fronterizas. La 
Ley de Tratados de 1992 intentó asimilar y regularizar esta práctica. Por principio de cuentas denominó "interinstitucionales" a estos acuerdos, y los definió como

el convenio regido por el derecho internacional público, celebrado por escrito entre cualquier dependencia u organismo descentralizado de la administración pública federal, estatal, o municipal y uno o varios órganos gubernamentales extranjeros y organizaciones internacionales, cualquiera que sea su denominación, sea que derive o no de un tratado previamente aprobado. ${ }^{77}$

También la Ley de 1992 obliga a las dependencias y autoridades listadas a registrar estos acuerdos en la Secretaría de Relaciones Exteriores.

Proceden las observaciones siguientes: $a$ ) Prosigue el vacío constitucional y no existe en la más alta jerarquía normativa una validación de los así llamados "acuerdos interinstitucionales"; b) La definición de "acuerdo interinstitucional" se acopla a la definición de "tratado" de la Convención de Viena de 1969 sobre el Derecho de los Tratados, y aclara que estos acuerdos están gobernados por el derecho internacional; es decir, les reconoce rango de tratados, por lo mismo, obligatorios para el Estado en su conjunto, aunque hayan sido celebrados por alguna autoridad aislada y aunque no hayan pasado por el Senado; c) De manera apropiada, la Ley indica en los artículos 6o. y 7o. que las autoridades facultadas para celebrar tratados interinstitucionales (secretarías de Estado, procurador general de la República, gobernadores de los estados, presidentes municipales) deben contar con un dictamen de la Secretaría de Relaciones Exteriores. Se entiende que es un dictamen a priori, y toda vez que estos acuerdos tienen rango de tratados y obligarán al Estado en su conjunto, la Secretaría de Relaciones Exteriores debe ejercer una supervisión celosa en la materia, máxime en épocas en las que los procesos de internacionalización comprometen a autoridades de nivel distinto en una aguda interacción. No sobraría que en estos casos de acuerdos interinstitucionales se informara de su celebración, junto con el dictamen correspondiente, al Senado de la República, a fin de que verificara su procedencia. La Constitución española ${ }^{78}$ contempla un mecanismo en este sentido: los tratados

78 Artículo 94.2, en Pastor Ridruejo, José Antonio, Curso de derecho internacional público y organizaciones internacionales, 6a. ed., Madrid, Tecnos, 1996, pp. 125 y 126. 
a los que no se exige la previa autorización de las Cortes deben ser informados inmediatamente al Congreso y al Senado.

Por otra parte, los “acuerdos interinstitucionales" regulan cuestiones administrativas, pero en el pasado el Ejecutivo ha firmado acuerdos bajo el nombre de "cartas de intención" o "entendimientos", que han regido sólo con la firma y han introducido al país reglamentaciones de alcance general en renglones tan variados como el comercio, la eliminación o la reducción de subsidios, precios de servicios, déficit fiscal, cuestiones financieras, pactados con otros Estados y con organizaciones como el Banco Mundial y el Fondo Monetario Internacional. Algunos pueden ser compromisos de emergencia, asumidos en momentos de crisis severas, cuando no hay otra opción, pero en otros casos los "entendimientos" o instrumentos semejantes, además de aceptar supuestos generales de regulación, pavimentaron el camino a una reorientación del modelo de desarrollo económico, con todas sus consecuencias en distintos órdenes de la vida nacional. Llamo la atención sobre el hecho de que el proceso del Tratado de Libre Comercio de la América del Norte se inició con compromisos del Ejecutivo, y fueron expresión de su preponderancia en la escena política, más acotada en años recientes por el devenir democrático del país. Definitivamente, este tipo de acuerdos deben rechazarse, y es menester destacar su naturaleza inconstitucional.

v) Algunas reflexiones adicionales sobre la conclusión de los tratados. Una vez aprobados los tratados por el Senado, el Ejecutivo no tiene la obligación de ratificarlos en el plano internacional, ni de hacerlo en un plazo determinado. No es usual que los tratados incluyan una cláusula sobre un tiempo determinado para que se confirme un tratado. Una curiosidad lo fue el artículo XXIII del Tratado de Guadalupe Hidalgo, que contemplaba el canje de ratificaciones a los cuatro meses de la fecha de la firma, y un artículo secreto ${ }^{79}$ preveía un lapso ampliado de ocho meses para el caso de que no se cumpliera con la condición original. Queda a criterio del Estado obligarse o no de manera definitiva por un régimen convencional, con base en su soberanía y en el principio ex consensu advenit vinculum, ${ }^{80}$ que reconoce al consentimiento como el cimiento de las obligaciones convencionales. Algunos tratados nunca son ratificados y

79 Por demás está decir que aunque no exista una previsión interna sobre la prohibición de tratados o articulados secretos, éstos están prohibidos en el derecho internacional.

80 Méndez Silva, Ricardo, "Los principios del derecho de los tratados", Boletín Mexicano de Derecho Comparado, México, nueva serie, año III, número 7, enero-abril, de 1970, pp. 93 y ss. 
otros pueden pasar décadas antes de que un Estado emita el acto confirmatorio.

Respecto a los tratados multilaterales y, aun de los bilaterales, se distingue la ratificación de la entrada en vigor de los mismos, sujeta a menudo a una fecha posterior del intercambio de ratificaciones, o en el caso de los multilaterales, al depósito de un número determinado de ratificaciones; ejemplo de ello, el Estatuto de la Corte Penal Internacional de 1998, que demanda para su entrada en vigor sesenta ratificaciones.

Ello puede presentar situaciones sui géneris. ¿Es vigente en el ámbito interno un tratado ratificado pero que todavía no ha entrado en vigor internacionalmente? La respuesta es especulativa. La letra del artículo 133 advierte sólo que los tratados "que se celebren por el presidente de la República, con aprobación del Senado", serán ley suprema de la Unión. Pero es obvio que un tratado exige la reciprocidad de las contrapartes y no puede prevalecer la unilateralidad. Me pregunto, sin embargo, qué pasaría con los tratados de derechos humanos que son una categoría ya diferenciada en el derecho internacional, con una índole distinta a los tratados tradicionales que han impuesto obligaciones a los Estados, mientras que éstos tienen como destinatarios a los individuos y se realizan para privilegiar sus ámbitos de libertad y de realización personal. La Corte Interamericana de Derechos Humanos ha trabajado esta distinción, ${ }^{81}$ y, con una concepción finalista, la protección de la persona humana, me atrevo a sostener que independientemente de su entrada en vigor internacional, un tratado debe considerarse obligatorio en lo interno.

Por otro lado, la situación de la denuncia de un tratado da pie a reflexiones. La denuncia es la forma unilateral para dar por terminado un tratado, pero en aras del principio del consentimiento, y para que sea válida jurídicamente es preciso que el tratado contenga una cláusula explícita en su articulado. Es frecuente que los tratados prevean que después de un cierto tiempo, cinco años, podría ser el caso, los Estados estén en aptitud de denunciarlo, dando un preaviso que puede ser de seis meses o un año. La terminación unilateral del tratado lo es sólo en su consumación, ya que es preciso que esté pactado en el mismo. Al aprobar el tratado, el Senado

81 "Al aprobar estos tratados sobre derechos humanos, los Estados se someten a un orden legal dentro del cual ellos, por el bien común, asumen varias obligaciones, no en relación con los Estados, sino hacia los individuos bajo su jurisdicción", en Salinas Rivera, Alejandro, "Chile, dos ejemplos de lucha contra la impunidad", Revista de la Comisión Internacional de Juristas, Ginebra, núm. 53, diciembre de 1994, p. 16. 
o el órgano Legislativo competente acepta esta posibilidad de terminación, y aunque no es usual que la denuncia se regule constitucionalmente, se le concede consuetudinariamente al Ejecutivo. Así, en un tratado que es ley suprema de la Unión, en el que no participó la Cámara de Diputados, sino únicamente el Senado, puede ser dado por concluido tan sólo con el concurso del presidente de la República. Los casos recientes de Jamaica y de Perú, al retirarse de la Corte Interamericana de Derechos Humanos, ilustran de los retrocesos preocupantes en esta materia. Lo prudente sería que para la denuncia de un tratado se siguiera el mismo trámite que para su celebración; esto es, en nuestro régimen prevaleciente, aprobación primero del Senado y después la denuncia a cargo del Ejecutivo.

Tratados prohibidos. Como quedó asentado, la carta magna recogió el artículo 15 de 1857 sobre la prohibición de celebrar ciertos tratados relacionados con las garantías individuales. Es oportuno indicar que en la prohibición de celebrar tratados que permitan la extradición de reos del orden común que en su país de origen hayan tenido la condición de esclavos, deberá entenderse la figura de la esclavitud, por desgracia vigente todavía en varios confines del mundo, en un sentido amplio, no únicamente en el de apropiación y cosificación jurídica de una persona, sino las prácticas equiparables, identificadas por la Organización de las Naciones Unidas, la explotación del trabajo infantil, el reclutamiento obligatorio de niños en el servicio militar, la trata de personas y la explotación sexual, incluyéndose la pornografía, sobre todo de los menores de edad, la venta de niños, la servidumbre por deudas, el apartheid y el colonialismo, así como las formas serviles de matrimonios. ${ }^{82}$

Puede deducirse, de lo advertido en la Ley de Extradición Internacional Mexicana que norma la materia, y es base de la cooperación internacional, que también estaría prohibido celebrar tratados de extradición o incluir en ellos cláusulas que favorecieran la extradición de personas que hayan sido objeto de absolución, indulto o amnistía, o cuando la persona reclamada hubiera cumplido la condena relativa al delito que motive la petición. ${ }^{83}$ La misma ley incluye otros supuestos derivados de las garantías judiciales, y es expresa cuando apunta que la extradición no se concederá si el delito que se imputa a la persona es del fuero militar. ${ }^{84}$ Un caso

82 Centro de Derechos Humanos de la Organización de las Naciones Unidas, Formas contemporáneas de la esclavitud, folleto informativo, Ginebra, núm. 14, 1991, 15 pp.

83 Artículo 7o., fracción I.

84 Artículo 9o. 
de singular interés proviene de la pena de muerte. El artículo 22 constitucional la permite; sin embargo, la legislación secundaria, salvo la del fuero militar, no la reconoce. La Ley de Extradición demanda que el Estado mexicano exija al Estado solicitante de una extradición que en caso de que en su legislación se permita la pena de muerte por el delito por el que es requerida una persona, se comprometa a no aplicarla. ${ }^{85}$

Por otra parte, en el derecho internacional se han consolidado las normas de jus cogens o normas imperativas de derecho internacional, entendidas como aquellas que no son susceptibles de ser derogadas por tratados o costumbres de los sujetos internacionales, a no ser que un nuevo tratado o una nueva costumbre asumiera el nivel de norma imperativa de derecho internacional. ${ }^{86}$ En tal sentido, el Estado mexicano estaría impedido de celebrar tratados, no sólo los de los casos previstos internamente por el artículo 15 constitucional, y los que versaran sobre las prohibiciones y limitaciones de la Ley de Extradición, sino aquellos que atentaran contra estos regímenes internacionales, señaladamente la prohibición del uso de la fuerza, la descolonización, los derechos humanos, el patrimonio común de la humanidad. ${ }^{87}$

Otra prohibición en la línea constitucional, ya identificada desde 1824, es la contenida en el artículo 117, que impide a las entidades federativas "celebrar alianza, tratado o coalición con otro Estado ni con las potencias extranjeras".

El artículo 133 fue una copia textual del 126 de la Constitución de 1857, que plasmó la cláusula de la supremacía normativa federal, y en la que los tratados figuraban como parte de la ley suprema de toda la Unión. A su vez, este texto, según quedó dicho, provenía de modo casi literal de lo contemplado en el artículo seis, párrafo dos, de la Constitución Norteamericana:

85 Ver, Gómez-Robledo Verduzco, Alonso, Extradición en derecho internacional, México, UNAM, 2000, p. 477.

86 La Convención de Viena de 1969 define así a las normas de jus cogens: "Para los efectos de la presente Convención, una norma imperativa de derecho internacional general es una norma aceptada y reconocida por la comunidad internacional de Estados en su conjunto como norma que no admite acuerdo en contrario y que sólo puede ser modificada por una norma ulterior de derecho internacional general que tenga el mismo carácter", artículo 53.

87 "La doctrina está lejos de mostrar acuerdo respecto a cuáles son las materias que quedan bajo el régimen de jus cogens". Respecto a las materias que enuncio, encuentro coindidencia con lo planteado por Pastor Ridruejo, op. cit., nota 78, pp. 66-70. 
Esta Constitución, y las leyes de los Estados Unidos que se expidan con arreglo a ella, y todos los tratados celebrados o que se celebren bajo la autoridad de los Estados Unidos, serán la Suprema ley del país y los jueces de cada Estado estarán obligados a observarlos, a pesar de cualquier cosa en contrario que se encuentre en la Constitución o las leyes de cualquier Estado.

El artículo 133 fue reformado el 18 de enero de $1934^{88}$ a fin de pulir la redacción, salvar la impericia de requerir la aprobación de los tratados por el Congreso, y, como una cuestión de fondo, aclara que los tratados deben estar de acuerdo con la Constitución. La versión actual, resultante de esta reforma, reza:

Esta Constitución, las leyes del Congreso de la Unión que emanen de ella y todos los tratados que estén de acuerdo con la misma, celebrados y que se celebren por el presidente de la República, con aprobación del Senado, serán la Ley Suprema de toda la Unión. Los jueces de cada Estado se arreglarán a dicha Constitución, leyes y tratados, a pesar de las disposiciones en contrario que pueda haber en las Constituciones o leyes de los Estados.

Existe una supremacía federal, pero en la cúspide de la pirámide jurídica prevalece la Constitución Política. En un escalón secundario se localizan la leyes del Congreso que emanen de ella y los tratados que estén de acuerdo con la ley suprema, aunque, como se ha advertido, una tesis reciente de la Suprema Corte de Justicia de la Nación concede primacía a los tratados respecto a las leyes constitucionales.

Exploro dos inquietudes: la primera vinculada con la jerarquía entre Constitución y tratado. El texto constitucional es claro al posicionar en una escala de preponderancia a la Constitución Política, pero los avances del derecho internacional han impreso un rango dominante a las normas convencionales sobre las del derecho interno. La Convención de Viena de 1969 sobre el Derecho de los Tratados sostiene que un Estado no podrá alegar una disposición de su derecho interno como medio para incumplir un tratado internacional. ${ }^{89}$ Todavía más, aun en el caso de las ratificaciones irregulares; esto es, la confirmación internacional de un tratado sin

88 Gómez-Robledo, Alonso, “Artículo 133”, Constitución Política de los Estados Unidos Mexicanos comentada, México, Instituto de Investigaciones Jurídicas, UNAM y Procuraduría General de la República, 1994, pp. 641-644.

89 Artículo 27. 
que se haya seguido el procedimiento interno previsto, la regla general adoptada por la Convención de Viena de 1969 es la validez del tratado, aunque la solución contemplada es en realidad una ambivalencia. ${ }^{90} \mathrm{Y}$ resulta que México es parte de la Convención. Puede alegarse que de acuerdo con el artículo 133 prevalecería la Constitución Política sobre la Convención de Viena, y salvarse de esta manera la contradicción, pero esto sería válido para el ámbito interno; en el plano internacional tendría fuerza jurídica prevaleciente el tratado. Además, desde la perspectiva política vivimos una época de intensa cooperación en la que los compromisos valen no sólo por la obligación jurídica, sino por el interés del propio Estado de no ser marginado de los distintos procesos de cooperación.

En tanto no se resuelva la contradicción entre las dos esferas normativas, la solución al alcance de un Estado, tal como se apuntó con antelación, es revisar meticulosamente su ordenamiento interno en relación con el tratado negociado, las posibles oposiciones terminológicas y conceptuales, las incompatibilidades regulatorias, ya que en una instancia judicial internacional se abrirán paso indefectiblemente los compromisos aceptados en un tratado.

La segunda inquietud se refiere a la jerarquía existente entre las leyes que emanan de la Constitución y los tratados. La redacción del artículo 133 no se pronuncia por la primacía de alguna de las dos fuentes. La Suprema Corte de Justicia de la Nación había sostenido tradicionalmente que leyes y tratados se encontraban en un plano de igualdad, y que los conflictos se resolverían con apego al criterio temporal de que ley la posterior deroga a la ley anterior. ${ }^{91}$ Es decir, la visión de la Suprema Corte se orientaba al principio de igualdad entre ambas fuentes. Desde esta perspectiva, la solución es otra vez interna, y la argumentación no resuelve el

90 El artículo 46, con escasa fortuna, abordó el punto: "Disposiciones de derecho interno concernientes a la competencia para celebrar tratados", y señala: "El hecho de que el consentimiento de un Estado en obligarse por un tratado en violación de una disposición de su derecho interno concerniente a la competencia para celebrar tratados no podrá ser alegado por dicho Estado como vicio de su consentimiento a menos que esa violación sea manifiesta y afecte a una norma de importancia fundamental de su derecho interno". Hay pues una regla general y una salida para la excepción. En realidad, en virtud de tal redacción, un asunto de esta índole deberá resolverse de manera casuística.

91 "Es pues, una regla de conflicto a que deben sujetarse las autoridades mexicanas, pero conforme a la misma no puede establecerse que los tratados sean de mayor obligación legal que las leyes del Congreso". Amparo en revisión, 191/81, Roberto Guadarrama Nicanor, 22 de julio de 1981, mayoría de votos. "Tratados internacionales. El artículo 133 constitucional, última parte, no establece su observancia preferente sobre las leyes del Congreso de la Unión emanadas de la Constitución Federal", en Guerrero Lara, Ezequiel, y Guadarrama López, Enrique, La interpretación constitucional de la Suprema Corte de Justicia, México, UNAM, 1985, pp. 23-45. 
conflicto entre la normatividad internacional y la doméstica, sea esta última del nivel constitucional o secundario.

En fecha reciente, el 11 de mayo de 1999, la Suprema Corte de Justicia de la Nación emitió una nueva tesis que se distancia del criterio antes expuesto. El vértice nutricio de la ley suprema de la Unión que reconocía dos estadios se ramifica en tres, ubicando en primer lugar a la Constitución, en el segundo, lo que implica una reconformación del orden jurídico tradicional, al tratado, y en una posición subordinada respecto a éste, a las leyes emanantes de la Constitución. La tesis 192-867 lleva por título: “TRATAdos INTERNACIONALES. Se UBicAN JERÁRQUiCAMENTE POR ENCIMA DE LAS LEYES FEDERALES Y EN UN SEGUNDO PLANO RESPECTO DE LA CONSTITUCIÓN FEDERAL". 92

El criterio ya ha dado de qué hablar, y se escuchan y se escucharán voces a favor y en contra. De una parte persiste el chauvinismo jurídico, con una legión nutrida de seguidores, para quienes resulta incomprensible que un tratado tenga preeminencia sobre las leyes que emanan de la Constitución, y por el otro están juristas con una visión actualizada de la intensa interacción entre los ámbitos internos e internacional.

Como sea, respecto a la tesis 192-867, todavía pueden pasar años para que se forme jurisprudencia y devenga obligatoria. También es posible que en otro asunto la Suprema Corte se incline por una postura distinta. Lo cierto es que la tesis en comento reconoce los crecientes, complejos y amplios compromisos que los Estados asumen en la sociedad contemporánea, más aún cuando destaca en el mundo una nueva generación de Constituciones internacionalistas, tal como las ha llamado el maestro Héctor Fix-Zamudio, que reconocen, bien la prioridad de los tratados o, al menos, su equiparación con la ley fundamental en materias delicadas como los derechos humanos. Bien vista, la tesis de 1999 es un avance notable. La interpretación de la Corte fue, más que en función de una estricta hermenéutica, en aras de la vida.

92 Sobre esta tesis de la Suprema Corte de Justicia de la Nación son altamente recomendables las siguientes notas: Becerra Ramírez, Manuel; Carpizo, Jorge; Corzo Sosa, Edgar; LópezAyllón, Sergio, en "Tratados internacionales. Se ubican jerárquicamente por encima de las leyes y en un segundo plano respecto de la Constitución federal (Amparo en revisión 1475- 98)", Cuestiones Constitucionales, México, núm. 3, UNAM, 2000, pp. 169-208. 


\section{CONCLUSIONES}

1. En los textos constitucionales el término usado a lo largo de la historia es el de "tratado", que es precisamente el que emplea la Convención de Viena de 1969 sobre el Derecho de los Tratados como el genérico.

2. Sería importante que se considerara la conveniencia de que la aprobación de los tratados fuese competencia del Congreso de la Unión, y no tan sólo del Senado.

Mientras ello pueda ocurrir, sería conveniente que el Senado creara un comité técnico especializado, para que hiciera una revisión técnica ponderada y concienzuda de los tratados a aprobar. Ésta es una práctica que se sigue en varios parlamentos del mundo en razón de la importancia de los compromisos que adquiere el Estado.

3. La experiencia histórica en los albores del constitucionalismo mexicano fue precisamente la participación del Congreso y es la tendencia de los regímenes federales o bicamarales en nuestros días. El punto es de interés porque hay materias competencia exclusiva del Congreso que pasan a ser ley suprema de la Unión en virtud de tratados que celebra el Ejecutivo con la aprobación del Senado.

4. Debería preverse en la Constitución la celebración de los acuerdos administrativos o interinstitucionales, acotándose el contenido susceptible de ser cubierto.

5. La tesis de la Suprema Corte de Justicia de la Nación sobre la jerarquía de los tratados en nuestro sistema jurídico es un avance sensible, en concordancia con los tiempos que se viven.

Me gustaría, sin embargo, que acorde con la tendencia de las Constituciones internacionalistas, los tratados, al menos los referentes a derechos humanos, tuvieran la misma jerarquía que la Constitución Política. México ha vivido grandes cambios en la arena política, y tal vez éstos se reflejen en la mentalidad y en las concepciones jurídicas que le cedan el paso a un nuevo escalonamiento de la pirámide jurídica. Aun en el campo del derecho, lo que se imagina termina por ocurrir. 